\title{
O LUGAR DO HOMEM NA NATUREZA
}

\section{Ana Tereza Caceres Cortez ${ }^{1}$}

Resumo: $O$ artigo discute a evolução de como o homem se insere e se vê inserido na natureza; suas interações com todos os elementos do meio ambiente e os impactos decorrentes dessa interferência. São analisados também o papel da tecnologia na apropriação e degradação dos recursos naturais e ao mesmo tempo, na busca de estudos e investimentos para o desenvolvimento de produtos e processos que objetivam recuperar $o$ meio ambiente para alcançar a qualidade de vida e qualidade ambiental.

Palavras-Chave: sociedade; natureza; impactos ambientais.

\section{MAN'S PLACE IN NATURE}

Abstract: The article explain on the evolution of the way how the man place himself and see himself placed in nature; its interactions with all the elements of the environment and the impacts originated of this interference. The study also analyzed the role of the technology in the appropriation and degradation of the natural resources and at the same time, in the search of studies and investments for the generation of products and processes with an objective to restore the environment to obtain the life's quality and environmental quality.

Key Words: society; nature; environmental impacts.

\section{INTRODUÇÃO}

Os graves problemas da exaustão dos recursos naturais e do saque dos ecossistemas ainda não estão satisfatoriamente investigados, devido às diferenças de formas de expressão comunicativa entre a natureza e o homem ou ainda por interesses econômicos imediatos particulares. Felizmente uma nova área de pesquisa está se abrindo para o historiador no campo das temáticas ambientais, ou seja, um estudo e uma análise da forma como os homens instituem suas relações sociais e seu modo de produção. Este último está diretamente ligado a um conceito holístico de investigação extremamente dinâmica das interações homem/natureza.

Em termos de interferência no meio ambiente, sabe-se que em um dado momento da história do homem sobre a terra ele podia ser considerado um elemento natural da mesma maneira que qualquer espécie animal. Evidentemente, que o homem primitivo não dispunha de uma quantidade de energia mecânica suficientemente grande para que seu

\footnotetext{
${ }^{1}$ Universidade Estadual Paulista -E-mail: atcortez@rc.unesp.br DOI: 10.7154/RDG.2011.0022.0002
} 
impacto sobre a natureza pudesse ultrapassar certos limites circunscritos. Já em 1975, Dubos salientava que existe apenas uma diferença de grau entre o cultivador neolítico desflorestando para obter uma clareira e o homem do ano 2000 que através de explosões atômicas, deslocará montanhas e modificará o curso dos rios obrigando-os a irrigar desertos. E realmente, é preciso reconhecer que essa diferença é fundamental, pois refere principalmente à rapidez das transformações, fator da maior importância quando analisamos o poder de assimilação dos impactos e a auto recuperação da natureza.

Com o aumento das densidades das populações humanas e sua organizando em comunidades sociais, cada vez mais aperfeiçoadas, estas rapidamente dispuseram de um poder crescente à medida que os seus recursos técnicos se desenvolviam. Tais fatos refletiam em uma maior pressão ao meio ambiente, onde a exploração dos recursos naturais e os diferentes tipos de rejeitos oriundos das diversas atividades transformaram completamente as paisagens originais num processo de contínua degradação. No fundo, a história da humanidade pode ser encarada como a luta da nossa espécie contra o meio em que se insere e a sua emancipação progressiva relativa à natureza e a algumas de suas leis. O domínio progressivo do homem sobre todos os elementos constitutivos do meio ambiente: o solo, os corpos aquáticos, as plantas e os animais, é um fato incontestável.

\section{A relação do homem com a natureza através dos tempos}

A relação da sociedade com a natureza, não se manifesta de maneira igual no espaço e no tempo. Em uma atitude simplista e objetiva é possível destacar três momentos da relação da espécie humana com a natureza: o homem amoldando-se a ela, o que podemos chamar de adaptação; o homem confrontando-se com a natureza, a que leva a uma posição de ataque à mesma (contra a natureza), e o homem restituindo os ambientes por ele degradados e preservando os que ainda restam (a favor da natureza).

Sabe-se que no início de sua aparição sobre a terra, uma fase de estreita subordinação o homem "sofreu" os imperativos de seu habitat natural. Nessa época, o homem procurou adaptar-se às condições oferecidas pelo meio, submetendo-se aos seus imperativos e modificando seu modo de vida em função dos climas e dos habitats onde se instalara. Mas esse período de adaptação foi relativamente curto, e rapidamente o homem contra atacou, exercendo uma série de ações às comunidades naturais a que pertence, passando a depredador e competidor. 
Essa adaptação das culturas humanas aos seus ambientes é originada pelas mudanças culturais. De acordo com Viertler (1988, p.20) "o processo de adaptação das culturas humanas do século $X X$ aos seus respectivos ambientes não significa que a convivência e a sobrevivência sejam "melhores" ou mais "vantajosas" para os indivíduos". Segundo a autora, adaptar-se significou em muitos casos, sobreviver por meio de numerosas concessões, por vezes com altos custos físicos e morais". Portanto, adaptar-se significa "lograr sobreviver", "não extinguir-se como cultura humana", e se esta adaptação representa um progresso, este é sempre relativo podendo muitas vezes, manifestar-se por perdas culturais ou involuções. Em suma, a adaptação é a inter-relação de culturas humanas e seus respectivos ambientes e não uma melhoria das condições de sobrevivência.

Na visão de Lima (1989), a revolução neolítica foi um marco na relação do homem com a natureza e determina o domínio biológico do homem sobre a reprodução de plantas e animais.

Até então, a relação homem $x$ natureza era de influência mútua de um sobre o outro, sendo que a natureza como um todo não se ressentia em face desta relação... Antes, a natureza, dominando todos os seres vivos, dominava o homem, trazendo-o subjulgado às relações que determinava o equilíbrio natural (LIMA, 1989, p. 155).

Ways (1970) citado por Chisholm (1974) enfatiza que existe uma tendência ocidental de objetivar a natureza para vê-la "do lado de fora", que é indiscutivelmente responsável pela forma arrogante e insensível de lidar com o mundo material. O autor salienta ainda que essa mesma atitude de separação do homem da natureza constitui a base do crescente conhecimento humano da mesma.

O método científico começou por separar para fins de estudos um aspecto da natureza do outro. Esse processo altamente eficiente de descobrir verdades solidamente verificáveis tende a ignorar tudo o que fique por fora de seu campo de ação, precisamente, por ter um enfoque tão dirigido. Chisholm (1974) destaca que o poder sobre a natureza foi conseguido por um alto preço e que

uma vez que o método e a ideologia dependiam do fracionamento dos fenômenos naturais em parcelas controláveis, em teorias e experiências antes de passar ao problema seguinte, o homem foi perdendo o sentido da vida como uma grande teia que é a que a Ecologia ensina (Chisholm,1974, p.11). 
Mas a ciência, procurando apenas o conhecimento, não é culpada da agressão direta contra o meio ambiente. A tecnologia, por seu lado, dedicada à ação, alimenta-se vorazmente das descobertas da ciência. Ainda que suas categorias não sejam as mesmas da ciência, a tecnologia, a seu modo, é também altamente especializada, orientada para fins estreitamente definidos. À medida que seu poder aumenta, e como as consequências estão fora de seu estreito campo de ação, proliferam "os efeitos colaterais" da tecnologia com impactos desastrosos para o ambiente.

Se considerarmos a sociedade capitalista, sabe-se que a ciência destina-se a gerar o saber necessário para garantir a produção e a reprodução dos processos vitais desta sociedade. Se a própria ciência tem um caráter de classe na sociedade capitalista, com mais razão o terá, a tecnologia, que é a aplicação dessa ciência ao processo produtivo.

Mas, dentro de todas essas ponderações, um fato é incontestável: o estado primitivo da natureza é modificado, quando não comprometido, logo que o homem disponha de meios técnicos um pouco mais aperfeiçoados e também, logo que a densidade de sua população ultrapasse um determinado limite. O homem pode definir-se como desestabilizador nato da terra e do céu, pois não se instala em nenhum trecho do planeta sem impor modificações em cadeia no meio natural.

A antropóloga Renate B. Viertler (1988), em seu livro Ecologia Cultural, subdivide os ambientes da vida das comunidades humanas em: ambientes naturais e ambientes humanos. Os primeiros correspondem a condições físicas associadas à fauna, à flora, aos recursos minerais e hidrográficos, característica dos solos e dos climas existentes nos territórios de exploração e de moradia das populações humanas. Segundo a autora, é interessante notar, que as culturas humanas nunca utilizam todos os recursos disponíveis no seu território de ocupação e sim, selecionam alguns deles em termos da tecnologia de que dispõe. A habilidade tecnológica nos leva a constatar a importância dos ambientes humanos. Estes são representados pelos antecedentes históricos das culturas que explicam a presença ou ausência de determinado padrão tecnológico, soluções socialmente herdadas. Os ambientes humanos, além das influências históricas, correspondem aos efeitos sociológicos, econômicos e políticos desencadeados pela sobrevivência amistosa ou hostil, de diversas comunidades culturalmente semelhantes ou não, engendrando as mais variadas modalidades de troca de recursos, indivíduos e conhecimentos. 
É inegável que as mudanças culturais sofridas pela humanidade alteraram de modo irreversível, as condições qualitativas e quantitativas da sobrevivência humana e do meio ambiente. Basta pensar, na grande diferença que existe entre uma pequena comunidade de caçadores do Paleolítico, época em que o homem ainda não conhecia a cerâmica, nem domesticava animais e cultivava plantas, e uma populosa sociedade industrial dos dias atuais, abastecida por uma agricultura mecanizada, pela domesticação dos animais, por modos de produção de artefatos materiais mediada por sofisticada maquinaria, por instituições político-econômicas de grande complexidade aglomerando grandes contingentes populacionais.

Na visão de Dorst (1973), já no fim do século XIX, nosso planeta estava entregue à "pilhagem" com a invasão do homem em todas as partes do mundo, explorando irracionalmente todos os ambientes. Segundo o autor, foi nesse momento que alguns homens lúcidos tomaram consciência da gravidade da situação e esboçou-se uma reação violenta, sob a influência de um pequeno número de naturalistas, iniciando-se a fase de proteção da natureza.

Essa tomada de consciência amplificou-se durante a Idade Média. Inúmeros textos legislativos foram promulgados pelos príncipes, visando a proteção da grande fauna da Europa e à conservação das florestas que, em outras zonas, estavam abatidas de forma generalizada. A maior parte dessas medidas tinha como objetivo principal a monopolização da grande fauna e preservação de terrenos de caça para o exclusivo benefício dos grandes da época (DORST, 1973, p. 91).

Se no início da fase protecionista, com exceção dos exploradores naturalistas, havia outros interesses que não propriamente a conservação da natureza, é possível considerar, que tais medidas acabaram protegendo a fauna de modo eficaz, moderando o processo de delapidação da natureza. Segundo Cortez (1994) a tomada de consciência tem sido registrada ao longo da história da humanidade em diferentes pontos e em diferentes momentos e paralelamente à exploração desmedida dos recursos naturais e a poluição ambiental, uma nova fase se inicia nas civilizações contemporâneas, que é a da preservação e recuperação dos ambientes degradados.

Atualmente, são observadas em todo o mundo inúmeras ações não somente de conservação como também de recuperação ambiental: recomposição de matas ciliares e outros tipos de áreas verdes; descontaminação de cursos d'água; reciclagem e reaproveitamento de 
materiais; criação de animais em cativeiro para a preservação da espécie; substituição de matérias primas com o objetivo de conservação dos recursos naturais entre outras.

Cortez (1987) já destacava que, em complementação a essas medidas, existe em todos os países um aparelho legislativo cada vez mais complexo, que se propõe a regulamentar a exploração dos recursos naturais, preservar a qualidade ambiental e submeter a regras precisas qualquer atividade que cause impacto ao ambiente e a população. O objetivo principal é a qualidade de vida da espécie humana, que agora, tem consciência da sua profunda ligação e dependência dos recursos da natureza.

\section{A delapidação da natureza e os modos de produção}

Lago e Pádua (1984), compartilham da idéia de que, o impacto do homem sobre o meio ambiente vai variar historicamente de acordo com o modo de produção, a estruturação das classes, o aspecto tecnológico e o universo cultural de cada sociedade.

Segundo Almeida (1988, p.13), "a noção de apropriação da natureza implica numa manipulação da mesma, subordinada aos fins propostos por seu dominador, que, em primeira instância, é o homem". Na natureza, repousam os elementos primordiais para a existência humana e os de todos os seres vivos, sendo, portanto, a fonte de subsistência continuadamente requisitada. Como já foi dito e o próprio Almeida enfatiza, a atividade definidora e determinadora de tal apropriação está diretamente ligada à organização de sua produção econômico-social, sendo o Capitalismo, em busca de lucro fácil e rápido, um dos sistemas dos mais lapidantes da natureza. No sistema capitalista, a extração de riquezas minerais, vegetais e animais é realizada sem haver uma preocupação com sua renovação Os elementos da natureza vão sendo destruídos segundo uma progressão geométrica de degradação. Marx (1985, p.51) enfatiza também a relação homem/natureza quando afirma: "o fato da vida física e espiritual do homem estar vinculada a natureza, não tem nenhum outro sentido a não ser que está vinculada consigo mesma, pois o homem é uma parte da natureza".

O grau de apropriação e destruição da natureza é definido pelas formas de produção e comercialização dos bens extraídos da mesma, e está diretamente vinculado com a tecnologia, fruto de uma organização social e mediadora da produção material. De acordo com Almeida, o conjunto de conhecimentos e instrumentos (tecnologia) utilizados nessa 
atividade mediadora, é utilizado corretamente para definir o grau de "desenvolvimento" de uma sociedade. As chamadas "sociedades primitivas", devido ao estágio de evolução da técnica dominadora da natureza, conseguiam com um mínimo de esforço produzir o suficiente para a sobrevivência.

Nesse momento, deve-se refletir sobre o papel do conhecimento e tecnologia com relação aos impactos das atividades do homem ao meio ambiente. Seria mesmo correta a afirmação de que "quanto maior o conhecimento humano e o nível tecnológico de suas sociedades, maior seria a degradação dos ambientes ocupados por essas sociedades"?. A tecnologia mais impacta negativamente o meio ambiente ou pode ser uma ferramenta de recuperação para áreas e ecossistemas degradados?

Segundo Dolce (2005) a tecnologia compreende o conjunto organizado de todos os conhecimentos científicos, empíricos e intuitivos usados para produzir e comercializar bens e produtos. A técnica, que não deve ser confundida com tecnologia, trata das habilidades de uso dos aparatos tecnológicos. Sem a compreensão histórica da tecnologia, torna-se difícil entender seu significado para a sociedade e para a conservação do meio ambiente.

No inicio da civilização humana, o homem conviveu com as tecnologias intuitivas, como por exemplo, a utilização do fogo, os primeiros utensílios, armas e ferramentas. Com o desenvolvimento de tecnologias e técnicas mais sofisticadas o homem foi, ao longo da história, se apropriando cada vez mais de algum bem natural para sua sobrevivência. Mas foi com o desenvolvimento das ciências e do método científico que esse processo se intensificou em benefício do homem.

A tecnologia que, ao mesmo tempo objetiva a melhoria da qualidade de vida da população e também delapída a natureza e degrada o meio ambiente, vem, agora, "acudir" a sociedade em um momento de crise socioambiental sem precedentes na história da humanidade. Assim tem-se a intensificação de estudos e investimentos na busca de produtos e processos que objetivam recuperar o meio ambiente e salvaguardar os recursos naturais, aliando o conceito de qualidade de vida ao de qualidade ambiental. Já Castro (1973) destaca que a tecnologia não é boa nem má, é a sua utilização que Ihe dá sentido ético. Se nos países do Terceiro Mundo a tecnologia age contra os povos subdesenvolvidos é porque foi utilizada unicamente para produzir o máximo de vantagens e lucros para os grupos da economia dominante 
Mas é importante lembrar que a sociedade atual produz não só para sobreviver, o que caracterizava as sociedades primitivas, mas para responder às necessidades sociais, que são criadas e diferenciadas culturalmente, dependendo de cada formação social; pode-se afirmar que as necessidades muitas vezes são frutos da imposição capitalista. Marx adota o conceito de valor de uso com uma perspectiva de utilização dos recursos naturais sob a ótica das "necessidades" sociais, isto é, criadas culturalmente que variam segundo as sociedades. Portanto, o capitalismo cria "necessidades" nas pessoas, que poderiam ser dispensáveis e assim, minimizar a explorarão degradante da natureza.

Conti (1986) lembra que o capitalismo obriga a agricultura substituir os adubos orgânicos pelos fertilizantes artificiais, provocando a erosão do solo e a eutrofização das águas; força o uso de defensivos como o DDT, que mata os pássaros insetívoros, a melhor defesa contra as pragas, e intensifica a resistência dos insetos, dando lugar a venda de venenos sucedâneos; as selvas do terceiro mundo não são poupadas pelas multinacionais, que necessitam de madeira e aumentar as áreas de pastagem, além de deteriorarem as cidades com todo tipo de poluição por suas indústrias.

É preciso ter o cuidado para não se atribuir exclusivamente ao capitalismo a responsabilidade pela delapidação das fontes de vida. Como salienta Kujawski (1980), para a "ecologia marxista" a redenção do ecossistema será impossível enquanto durar o processo capitalista de exploração do homem pelo homem, e da natureza pelo homem. Na visão do autor, não há duvida que o capitalismo pode ser culpado de muitos crimes, mas não o de matar as espécies: "A degradação geral da natureza, a poluição mundial, o desrespeito as fontes da vida são os males próprios da sociedade industrial moderna, seja qual for seu modo de produção" (KUJAWSKI, 1980, p.4). Nesse caso, o Socialismo não é mais isento de responsabilidades do que o Capitalismo. O imperativo de crescimento é um caráter comum da sociedade industrial moderna tanto no Capitalismo como no Socialismo. Segundo Raymond Aron (1982) o crescimento, embora seja um fenômeno mensurável, quantitativo, é determinado por fatores qualitativos. A dialética do crescimento, é condicionada por fatores qualitativos à maneira de ser e pensar dos homens. Portanto, está no alcance tanto do Socialismo, como do Capitalismo, tomar as providencias necessárias para corrigir a agressividade da economia contra o meio natural. Isso não significa que a sociedade contemporânea possa prescindir de tudo a que foi conquistado nestes últimos séculos para voltar ao primitivismo. Além do mais, existem determinadas matérias naturais que são 
indispensáveis às necessidades biológicas para a existência do ser vivo. Apenas, a sociedade deve esforçar para se organizar na produção e implementação de técnicas, de maneira que os ecossistemas sejam respeitados.

Na visão do antropólogo Pierre Clastres (1982), se nós entendemos por técnica, o conjunto dos processos de que se munem os homens, não para assegurarem o domínio absoluto da natureza, mas para garantir um domínio do meio natural adaptado e relativo às suas necessidades, então não mais podemos falar em inferioridade técnica das sociedades primitivas. Estas demonstram uma capacidade de satisfazer suas necessidades pelo menos igual aquela de que se orgulha a sociedade industrial e técnica. Portanto, de acordo com Clastres não existe hierarquia no campo da técnica, nem tecnologia superior ou inferior; só se pode medir um equipamento tecnológico, pela sua capacidade de satisfazer, num determinado meio as necessidades da sociedade. $O$ autor enfatiza que o homem se apropria da natureza, não pelo simples prazer de dominá-la, mas para suprir suas necessidades (criadas ou não) que, com o tempo tornam-se cada vez mais crescentes, tanto em termos quantitativos, como qualitativos.

\section{O meio ambiente, o homem e as outras espécies animais}

É importante ponderar que a relação homem/natureza ocorre simultaneamente e necessariamente se interagem produzindo e resultando ações advinhas deste relacionamento, independente das diferenças de posicionamento entre os cientistas sobre a categorização das sociedades por meio da hierarquia tecnológica. Qualquer que seja o nível de desenvolvimento de uma sociedade, as interações entre o homem e o meio ambiente são permanentes, intensas e íntimas.

Essas interações são de tal intensidade que, o ambiente é entendido por muitos, como o todo, o conjunto das manifestações da vida no planeta; o homem na biosfera. Destacandose ainda, a noção de que não se distingue um meio ambiente humano e um meio ambiente físico a comporem a biosfera. O ser humano e a biosfera configuram uma unidade, um ambiente único, que é o ambiente que nos explica no universo. Nessa concepção, fazemos parte de um ambiente constituído por componentes indissociáveis: o meio natural e o meio cultural, mas inteiro como ambiente, como um só lugar para a vida da humanidade.

Para Almeida (1988), o fator diferenciador da relação homem/natureza é a consciência, exemplo da singularidade humana composta pela cultura e raciocínio. A ação que o homem 
exerce sobre a natureza, e, portanto, sobre si mesmo, enquanto pertencente a ela, é dirigida para determinados fins.

Para sua sobrevivência, necessariamente o homem relaciona-se com a natureza, desestabilizando-a, pois não retira somente o necessário para a sua reprodução física, mas para satisfazer as necessidades socialmente fabricadas. E se perguntarmos à qualquer ser, humano sobre a existência das coisas, a resposta geral é que tudo na natureza foi criado para nosso auxílio e uso prático. Todo o cenário magnífico proporcionado pelos elementos naturais é diária e confiantemente visto como destinado à conveniência peculiar do gênero humano.

O biólogo Jakok Von Uexüll (1982) há mais de setenta anos, demonstrou que a realidade do meio ambiente não é tão simples quanto parece. Na aparência, o meio ambiente é um fenômeno que "já está ali", como um cenário vazio e idêntico para todas as espécies. Segundo a biólogo alemão, essa imagem não procede, pois o meio ambiente surge da ação biológica da espécie sobre o contorno, formando com este um todo funcional no qual não há vazios, nem separação entre o corpo vivo; o meio acontece diversamente para cada espécie. Cada qual tem seu meio próprio e exclusivo, o que não impede que se associem na totalidade superior do ecossistema. Portanto, na teoria de Von VexKull, o "habitat" constitui-se pelos elementos que o ente vivo de determinado tipo percebe no contorno, aos quais está funcionalmente aderido.

Kujawski (1980) não concorda que essas afirmações possam também, serem aplicadas com relação à espécie humana, simplesmente porque o homem não conhece a ação biológica puramente instintiva. O autor salienta que, no homem, a ação biológica manifesta-se complicada com a ação racional, entremeada de hesitações, opções, ponderação, avaliação, cálculo e planejamento. Ao sair das relações sensitivas originais das ações biológicas instintivas, o homem tenta construir as ações de fora, à base de ponderação e planos. Não há continuidade antológica entre o ser humano e a natureza; a solução de continuidade é esperada pela razão, conforme esta substitui a resposta inteligente, inventiva, criadora. A partir dessas idéias, Kujawski conclui que o homem está fora da natureza, sendo, portanto, a única espécie conhecida que não tem "habitat" próprio, ao qual se conjuga funcionalmente. Assim, sem "habitat" ao qual se inclua, solto e livre em toda a extensão da terra, o homem não passa de um estranho no ninho da natureza. 
A esse respeito, o antropólogo Teilhard de Chardin em sua obra "O Fenômeno Humano", observa que não há nenhum traço anatômico ou fisiológico que distinga o homem dos outros animais superiores. Não obstante, o homem exibe uma característica zoológica que o faz um ser à parte no mundo animal: é o único que habita todo o planeta. Ao contrário das outras espécies que vivem circunscritas em seu "habitat", a homem é encontrado em todas as regiões do globo; é um ser ecumênico. O filósofo espanhol Ortega y Gasset (1951), explanou que o fato do homem habitar onde quiser, sua planetária ubiquidade, significa que este carece propriamente de "habitat", de espaço onde, sem mais, possa habitar. A terra é para o homem, originalmente inabitável e, para subsistir, intercala em todos os lugares terrestres e sua pessoa, criações técnicas, construções que deformam, reformam e conformam a terra, de sorte que resulte mais ou menos habitável. Segundo esse estudioso, o homem é um intruso na chamada natureza, vem de fora dela e essencialmente inadaptado a todo meio. Por isso constrói e, como pode construir em qualquer lugar do planeta - e em cada um, diferente tipo de construção - é capaz de habitar em todas as partes.

Com relação à adaptação do homem ao ambiente, Mencken (1988) tem uma visão interessante e que deve levar a muitas reflexões. Ele salienta que nenhum outro animal é tão incompetente para se adaptar ao seu próprio ambiente como o homem. Como exemplo, cita a criança, que, quando vem ao mundo, é tão frágil que, se for deixada sozinha por aí durante dias, infalivelmente morrerá, e que essa enfermidade congênita, embora mais ou menos disfarçada depois, continuará até a morte. O autor comenta ainda que o homem adoece mais do que qualquer outro animal; sofre de uma variedade maior de doenças e com mais frequência; cansa-se ou fere-se com mais facilidade e finalmente, morre de forma horrível e geralmente mais cedo.

Com essas ponderações, a conclusão que se chega, é que o homem é um ser essencialmente desambientado, inadaptado a natureza, que não é para ele seu ambiente natural. A natureza assalta o homem como um repto exigindo respostas e este responde de acordo com seu peculiar ideal de vida, ou, como salienta Ortega, segundo a "inspiração histórica", que é o projeto vital de um povo.

Também Toynbee (1946) atribuiu a origem e sobrevivência das civilizações ao princípio da "incitação e resposta" (challenge e response), uma sofisticação do pensamento darwinista que mencionava a luta pela sobrevivência, incluindo nela esse mecanismo como o verdadeiro motor do crescimento das civilizações. Em seus estudos, esse autor fez uma 
relação entre o desempenho da civilização e as exigências da Botânica: as civilizações podem decair, mas reagem, lançando-se em recuos táticos, para depois, recuperadas, voltar normalmente a ascender. Em seu primeiro momento, a natureza representa para o homem, não um ambiente ideal como a água para o peixe, mas sim, um grande e total desafio. Toynbee admite que o contorno físico engendra as civilizações não diretamente por ser favorável, mas precisamente na medida em que se declara hostil para o homem, propondose, como desafio, repto à sobrevivência.

Essa idéia já fora enunciada por Ortega Y Gasset, em 1922, onde pondera que a paisagem não determina casualmente, inexoravelmente, os destinos históricos e que a Geografia não arrasta a História, somente a incita. O autor destaca ainda que cada povo encontrou-se com seu problema, planteado pelo território que chegou, e o resolveu à sua maneira, uns bem outros mal. O resultado dessa solução são as paisagens atuais. A esse respeito, Kujawski pensa que se deve inverter os termos. Segundo o autor, o dado geográfico é muito importante para a história, mas não é aproveitável como causa que explica o caráter de um povo e sim, ao contrário, como sintoma e símbolo desse caráter. Cada raça leva em sua alma primitiva um ideal de paisagem que se esforça por realizar nas fronteiras geográficas do contorno.

\section{Ambiente e organismo: circunstância e projeto?}

Com todas essas reflexões, chega-se a conclusão que os preceitos da Ecologia precisam ser retificados: a natureza não é ambiente onde o homem entra como os dedos na luva mas problema, desafio, circunstância; e por outro lado, o homem não é organismo e sim projeto. Portanto, se essas colocações forem consideradas, ao invés de se utilizar os termos, ambiente e organismo, tão comuns na ciência ecológica, é preferível falarmos em circunstância e projeto, como propõe Kujawski. Não há harmonia natural pré-estabelecida entre o homem e a natureza; o que se verifica é o embate incessante, a luta muitas vezes milenar entre o projeto de instalação humana no contorno e a adversidade da natureza, o corpo a corpo entre o homem e sua circunstância. A única harmonia possível entre ambos é de ordem não natural, mas cultural e a "posteriori". A ruptura do homem com a natureza, sempre existiu como nota essencial da condição humana. Assim sendo, o homem não pode "voltar" a natureza, porque nunca, a rigor, foi membro dela. 
Mas nem todos os profissionais envolvidos com os estudos da relação homem/natureza, compartilham dessas idéias. Dorst (1973, p.334), por exemplo, afirma que "já não é possível dissociar o homem do meio natural de onde não pode ser omitido nenhuma espécie animal ou vegetal, cada uma delas intervindo parcialmente num vasto equilíbrio". O autor salienta ainda que o homem e o conjunto da criação formam um todo e que salvação do homem exige a sua harmonia com a natureza.

Sob ótica de Kujawaski, também o mito do "equilíbrio ecológico" é desmentido, através das idéias de descontinuidade entre o homem a natureza. De acordo com Kenneth Boulding, citado por Chisholm (1974, p.11):

A verdade é que não tivemos ainda um estado de equilíbrio em nosso universo durante três e meio bilhões de anos e não é agora que vamos começar. A vida é um processo evolucionário. A idéia de que é possível conseguir um equilíbrio e mantê-lo, é apenas tolice rematadas especialmente com uma criatura como o homem.

\section{CONSIDERAÇÕES FINAIS}

Com todas essas ponderações, a conclusão que se chega é que existe uma grande e comum preocupação com o perigo do esgotamento dos recursos naturais dos quais dependem todas as espécies de seres vivos, e a extinção até da própria espécie humana. Nesse momento uma reflexão toma conta de muitos setores da população, em especial cientistas e pesquisadores: onde está a lógica e a razão em promovermos a destruirão da meio ambiente, se estamos intimamente dependentes e vinculados a ele? Afinal, somos partes integrantes desse meio, e, como tal dependemos dele..

O "homem é uma parte deste universo e é composta por ele, no entanto, ele se autodeclara ter o poder de estipular a importância dos outros componentes em relação a seu interesse" (ALMEIDA, 1988, p.22).

Através das atitudes do homem com relação a natureza, fica evidenciado que seu relacionamento biológico-psicológico com o meio ambiente passa a ser, inevitavelmente, completado pelo relacionamento cultural. Portanto, apenas como ser biológico, o homem pode ser comparado com os outros animais: ele nasce, se desenvolve, utiliza-se dos elementos da natureza para esse desenvolvimento, se reproduz e morre.

Desde os tempos mais remotos, o homem buscou na natureza formas de sobrevivência: abrigo, alimentação, defesa, cura para suas doenças. O diferencial que marcou a relação de 
equilíbrio ou desequilíbrio do homem com a natureza, foi o objetivo da retirada ou apropriação dos bens da natureza. Na situação de equilíbrio, visava satisfazer suas necessidades básicas; já na relação de desequilíbrio, o objetivo era a produção de excedentes e não mais sua subsistência.

Com as observações de Mencken, talvez se possa explicar a razão da supremacia do homem sobre a terra, mesmo com sua natural inaptabilidade ao meio e sem os dotes físicos dos outros animais: o homem faz uso da razão, da organização social do trabalho e das técnicas cada vez mais sofisticadas.

Muito apropriada a idéia de Machado (1988) quando afirma que do meio ambiente o homem retira os recursos indispensáveis à sua sobrevivência e atua nele, criando e recriando suas paisagens; se diferenciando dos outros animais porque não somente respira e come frutos, mas sonha e projeta possíveis transformações no meio ambiente e realiza criativamente, algumas delas, para viver, como indivíduo e como comunidade, em suas paisagens assim criadas e por ele escolhidas. Como a autora pondera, o homem pode moldar o futuro por meio de decisões relativas ao meio ambiente, criar paisagens e a elas adaptar-se, o que exprime uma continua interação com o meio onde está inserido.

Gilberto de Mello Kujawaski, tem um posicionamento muito interessante sobre o lugar do homem na natureza:

Nem o homem é simples "organismo", nem a natureza simples "ambiente", ao qual estaria naturalmente conjugados como o animal ao seu habitat. 0 homem é projeto, impulso de liberdade, e a natureza não é seu ambiente, sua casa prontinha para recebê-lo, mas circunstância adversa a ser moldada e estruturada em moradia para o homem de acordo com sua imprevisível e variável fantasia cultural ... A natureza científica do Biólogo e a natureza utilitária dos economistas tem de ceder lugar à natureza da pensador, do artista, do esportista, do homem religioso, do homem comum para que este não se dissolva no niilismo, mas assegure um pouco de sua autoidentidade ao nascer, viver e morrer à sombra das mesmas árvores (KUJAWSKI, 1980, p.4).

\section{REFERÊNCIAS BIBLIOGRÁFICAS}

ALMEIDA, J.P. A extinção do arco-íris: ecologia e história. Campinas: Papirus, 1988.

ARON, R. Dez Lições sobre a sociedade industrial. São Paulo: Martins Fontes, 1982. 
CASTRO, A. M. Subdesenvolvimento: causa primeira de poluição. O Correio da UNESCO, Paris, ano 1, n. 3, mar. 1973.

CHARDIN, T. O Fenômeno Humano. São Paulo: Cultrix, 1988.

CHISHOLM, A. Ecologia: uma estratégia para a sobrevivência. Rio de Janeiro: Zahar, 1974.

CLASTRES, P. A sociedade contra o estado. Tradução de Theo Santiago. 2. ed. Rio de Janeiro: Francisco Seves, 1982.

CONTI, L. Ecologia - capital, trabalho e meio ambiente. São Paulo: Hucitec, 1986.

CORTEZ, A. T. C. A legislação ambiental no período de 1934 - 1984. Geografia. São Paulo, V 5/6, p.7-27, 1987.

A natureza, a sociedade e as leis ambientais. Boletim Informativo. Centro de Estudos Ambientais. Rio Claro, n.5, p. 7, 1994.

DOLCE, J. Tecnologia. Disponível em:

<http://www.esg.br/datec/palestras/cbct99/ct99.html> Acesso em: 20 mar.2005.

DORST, J. Antes que a natureza morra. São Paulo: Edgard Büicher; EDUSP, 1973.

DUBOS, R. Namorando a terra. Tradução de Maria Cristina Carnevale. São Paulo: Melhoramentos; EDUSP, 1975.

KUJAWSKI, G.M. Ecologia: qual o verdadeiro lugar do homem? O Estado de São Paulo, São Paulo, Caderno 2, ano 1, n. 4, p. 4, 06 jul.1980.

LAGO, A; PÁDUA, J.A. O que é ecologia. São Paulo: Brasiliense, 1984.

LIMA, S. do C. A relação sociedade \& natureza. Sociedade \& Natureza, Uberlândia, n. 2, p. 155-163, 1989.

MACHADO, L.M.C.P. A Serra do Mar Paulista: um estudo de paisagem valorizada. Rio Claro, 1 v. Tese (Doutorado em Geografia) - Instituto de Geociências e Ciências Exatas, Universidade Estadual Paulista, 1988 
MARX, K. O Capital. Tradução de Régis Barbosa e Flávio R. Kothe. 2. ed. São Paulo: Nova Cultural, v. 1, Livro 1, 1985.

MENCKEN, H. L. O livro dos insultos. São Paulo: Companhia das Letras, 1988, 248 p.

ORTEGA Y GASSET, J. En torno al coloquio de Darmstadt. Madri: O.C., 1951, v.9. Temas de viaje. Madri: O.C., 1922, v.2.

TOYNBEE, A. A Study of History. New York: Oxford University Premir, 1946.

VIERTLER, R.B.V. Ecologia Cultural: uma antropologia da mudança. Série Princípios. São Paulo: Ática, 1988.

VON UEXKÜLL, J. Dos animais e dos homens. São Paulo: Livros do Brasil, 1982, 272 p.

Artigo recebido em 24/08/2011.

Artigo aceito em 30/10/2011. 